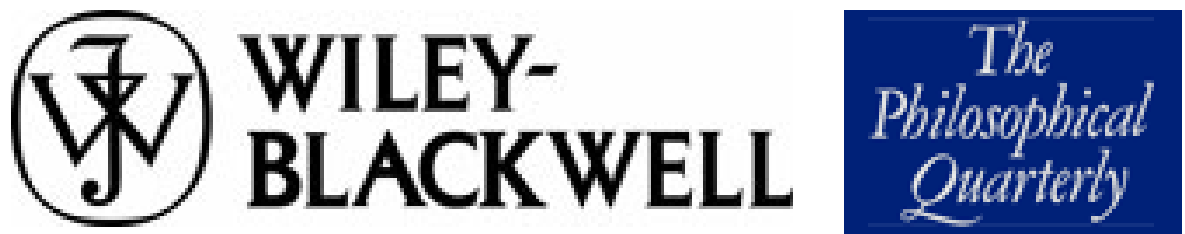

\section{Bad Samaritans Cause Harm}

Author(s): John Harris

Source: The Philosophical Quarterly, Vol. 32, No. 126 (Jan., 1982), pp. 60-69

Published by: Blackwell Publishing for The Philosophical Quarterly

Stable URL: http://www.jstor.org/stable/2219001

Accessed: 11/05/2009 10:03

Your use of the JSTOR archive indicates your acceptance of JSTOR's Terms and Conditions of Use, available at http://www.jstor.org/page/info/about/policies/terms.jsp. JSTOR's Terms and Conditions of Use provides, in part, that unless you have obtained prior permission, you may not download an entire issue of a journal or multiple copies of articles, and you may use content in the JSTOR archive only for your personal, non-commercial use.

Please contact the publisher regarding any further use of this work. Publisher contact information may be obtained at http://www.jstor.org/action/showPublisher?publisherCode=black.

Each copy of any part of a JSTOR transmission must contain the same copyright notice that appears on the screen or printed page of such transmission.

JSTOR is a not-for-profit organization founded in 1995 to build trusted digital archives for scholarship. We work with the scholarly community to preserve their work and the materials they rely upon, and to build a common research platform that promotes the discovery and use of these resources. For more information about JSTOR, please contact support@jstor.org. 


\section{DISCUSSIONS}

\section{BAD SAMARITANS CAUSE HARM}

\section{By JoHN HARRIS}

Two recent papers have argued that there is no such thing as negative causation or causal responsibility for omissions, and consequently no such things as negative responsibility or negative actions. Eric Mack and Elazar Weinryb thus conclude that so-called "Bad Samaritan" legislation is indefensible. ${ }^{1}$

Their view has dramatic consequences. If I save your life by telling a lie, saving your life is something I have done and can be responsible for. Conversely, if I tell the truth and as a result you die, I have caused your death and can be similarly responsible. But now, if only my silence can save you, and knowing this I keep quiet, then on the Mack-Weinryb account I haven't saved you after all. Similarly, if I could save your life by speaking out, but remain silent, I cannot have been causally responsible for your death and cannot thus be morally responsible either (assuming that $I$ have no independent duty to save you nor no role-responsibility for you).

An even more unsatisfactory consequence of this view is that where either keeping silent or telling a lie will save your life, if I wish to save your life I must not remain silent rather than tell a lie, for remaining silent is not a way I have of causally influencing events. Mack and Weinryb would be forced to recommend lying to those who wish to save others in such circumstances; and needlessly, since keeping silent and telling a lie are here both equally effective ways of saving life.

It would certainly be worth examining the arguments that have led to these strange conclusions even without the added spur of Mack's and Weinryb's having developed them in answer to my own defence of negative responsibility. ${ }^{2}$ So we will look at their arguments and then turn to the ingenious attempt of Douglas Husak to side-step this debate about the causal efficacy of omissions. ${ }^{3}$

Mack's purpose is to criticise the view that harm (and other things) may be caused by omissions or negative actions, which he calls "the causation thesis"'. He deploys two arguments against it:

(1) "The causation theorist cannot avoid commitment to the very general claim about negative causation that any absence of an action (or event) is a cause of outcome $Y$ if that action or event would have prevented $Y$ " (p. 241).

1Eric Mack, "Bad Samaritanism and the Causation of Harm", Philosophy \& Public Affairs, 9 (1980), 230-59; Elazar Weinryb, "Omissions and Responsibility", The Philosophical Quarterly, 30 (1980), 1-18.

2John Harris, "The Marxist Conception of Violence", Philosophy \& Public Affairs, 3 (1974), 192-220.

'Douglas N. Husak, "Omissions, Causation and Liability", The Philosophical Quarterly, 30 (1980), 318-26. 
(2) The acceptability of the causation thesis depends upon a sceptic "being presented with cases about which he agrees that it is natural to speak of $A$ 's non-doing as being responsible for, indeed being the cause of, $B$ 's injury and for which he has no alternative explanation of why it is natural to speak in this way" (p. 242).

Mack concludes that "the fact of the matter is that whenever the sceptic finds himself tempted to speak in terms of non-doings being responsible for an injury, he will be able to reconstrue the case in a way that does not involve negative causation." According to Mack this can happen in two ways. Either the sceptic will "insist that it is not the agent's inaction but rather that agent's prior actions which cause the injury" (Tactic A) or he "will maintain that speaking of responsibility or causation is just a way of our ascribing blameworthiness and does not involve a genuine causal judgement at all" (Tactic B) (ibid.).

\section{Argument (2)}

To take Mack's second argument first, it seems natural in the example with which we started to talk of my being causally responsible for your death if I keep silent when, by speaking out, I could save your life (say, when I am your alibi to a capital charge of which you are innocent and where I have done nothing to incriminate you or otherwise bring about your arrest and where I have no special duty to or responsibility for you).

\section{Tactic A}

Why should the fact that the agent's prior positive actions have made a contribution nullify the effect of his subsequent negative actions? Mack gives an example:

When a hunter innocently wounds a bystander, it is not that a sui generis duty to care appears in virtue of which the hunter must lift the bystander's face out of the puddle in which he has fallen unconscious and in virtue of which the hunter's inaction causes death. If the hunter wanders on, his shooting the bystander causes his drowning. (pp. 240-1)

But, whereas the hunter innocently shot the bystander he did not innocently leave him to drown, so we can say the shooting was an accident but the drowning not. Certainly Mack can say that the shooting caused the drowning, but that is not to say that the decision to leave the bystander to drown played no part. How should an innocent hunter impressed by Mack's arguments reason? He will say, "I have already done all that is in my power by superficially wounding the bystander. If I now do not lift the bystander's head from the puddle that cannot affect my responsibility for his fate, for it is neither an action nor an event which can affect the bystander in any way". But the hunter will surely and rightly see that his shot has only slightly wounded the bystander, that he can still save him and can still bring about his death. But not all the prior interventions of agents are like this.

Say, you and I are dining together alone and you begin to choke on your food and I sit by calmly finishing my dinner and watching while you choke to death, when I could easily save you. On Mack's view my failure to save you makes me causally responsible when the dinner is at my house and it was I that failed to remove all the fish bones (and so by my prior actions caused the injury), but not when we are eating chez vous and it was 
your prior actions which caused the choking. Mack's escape from this bizarre conclusion is that in neither case is anyone responsible for your death because the prior "actions" were all omissions! Only if I, not you, put bones in a boneless fish (for decoration, not murder) can I on Mack's view become responsible, causally or morally, when I let you choke to death.

It is far from clear then why the sceptic's first tactic has any force. If it is the failure to prevent the harm that is in each case what makes the difference between disaster and no disaster, or between mild injury and death, why is it only when the negative agent has made a prior appearance in the drama that her actions have the requisite causal impact on events?

Mack employs this first tactic against a passage in illustration from Engels.4 Re-quoting the passage he notes the claim that "Murder has been committed if thousands of workers have been deprived of the necessities of life or if they have been forced into a situation in which it is impossible for them to survive", and comments, "But the activities here described would be no more inactions than would my stripping someone of his provisions, placing him in a cell, booby-trapping the exit and then "merely" leaving him there to starve" (p. 242). Certainly this passage taken in isolation bears Mack's interpretation, but it also bears the one that I had placed on it, namely that it was capitalist society which in the person of landowners and industrialists "deprived the workers of the necessities of life" by failing to pay a living wage, and which in the person of the government "forced them into a situation in which it was impossible for them to survive", by failing to implement social welfare legislation. It was these failures and neglects and not gunpoint and the like which did the forcing and the depriving. I leave it to readers of Engels as to which interpretation of his words best captures his meaning.

So, it is far from clear why the first tactic is damaging to negative causation, and we are left with the second tactic or failing that the first argument.

\section{Tactic B}

This tactic is succinctly stated and employed by Mack:

The waters are even more muddied when advocates of the causation view cite cases in which our willingness to say that in failing to act $A$ causes harm $Y$ is our way of affirming the moral faultiness of $A$. This type of causal-sounding, ascription of blame appears in Harris' recounting of a broadcaster's comment following the massacre by the Lod airport suicide squad: "Don't tell me anyone searched the suitcases of those men - whoever let them on the plane is also guilty of murder". This case also rides on the existence of the special obligations of inspection officials. (p. 243)

The force of this is entirely opaque. Why on earth should we blame $A$ for failing to act (in the absence of his having a duty so to do) unless we see that the consequences of this failure are significant? That is, simply, unless this failure does have consequences. The case does not necessarily ride on the existence here of special obligations. It means precisely what it says, that "whoever let them on the plane . . .". I don't know what provision for inspection obtained at Lod, but the witness need not have been referring to the negligence of officials appointed to search passengers, but rather have been criticising the failure to appoint any such officials. My point is that the most obvious reason for finding moral fault with people who fail to pre-

"Quoted in "The Marxist Conception of Violence" (note 2). 
vent harm is that the harm is a consequence of their failure. There are other reasons of course, but this is perhaps the most natural and we should not lightly abandon it.

\section{Argument (1)}

We can now turn to Mack's first argument. This is developed as part of his attack on my original formulation of "negative causation" and "negative action" which was indeed both imprecise and incomplete. 5 I don't wish to get bogged down in a blow by blow rebuttal or concession of Mack's points but to concentrate on the general issues.

Mack's first argument centres then on the claim that anyone who accepts negative causation is committed to the very general thesis that any absence of a preventing act or event is a cause, whether or not this action or event was possible at all. The problem that Mack then poses for a negative-action theorist is: What licenses the promotion of any one of the infinite number of causally necessary conditions to the status of a cause or the cause of anything? This is the same problem that is often put the other way about as: What licenses the restriction of negative causes to a manageable group?

Mack deploys a number of ingenious arguments to establish this point, which he obviously regards as embarrassing for negative-action theorists. The question of what licenses the promotion of a causally necessary condition to the status of $a$ cause or the cause is undoubtedly complex. There is almost certainly no single answer nor even a single type of answer. We should however remember that this is a general problem about causation and not one for negative causation alone. Chains of positive causation are indefinitely long; each link is a causally necessary condition and we must pick particular candidates from among them.

If we are not sufficiently embarrassed by the general argument, Mack has a more specific suggestion as to why we should not promote absences of causally possible actions or events to the status of the cause of anything. The argument concerns Smith's death by drowning and Jones' failure to rescue him. It goes as follows:

If one concedes that conditions not including the absence of rescue actions are jointly sufficient for Smith's drowning when Jones' refraining from rescue activity is not possible, then why believe that the factor which renders this refraining possible also has the effect of rendering previously jointly sufficient conditions for Smith's drowning insufficient for that harm? To believe that . . . is to be committed to [the] proposition . . . that the factor which transforms the situation into one in which refraining is possible (for example, Jones notices the struggling Smith, Jones comes to believe that he can save Smith) has the specific effect of altering the causal sufficiency of that group of conditions previously sufficient for the drowning. (p. 255)

The argument here is borrowed from Professor Anscombe and concerns what Mack calls "believable effects". ${ }^{6}$ Mack's suggestion is that it is not believable.that, for example, changing one's beliefs could alter the causal sufficiency of massive natural effects like wind and tide. But of course wind and tide are not causally sufficient of themselves unless they are sufficient to frustrate any rescue attempt whatsoever. It is only if nothing could save $1980)$.

${ }^{5} \mathrm{I}$ hope that I have now corrected this in my Violence and Responsibility (London,

${ }^{6}$ G. E. M. Anscombe, “A Note on Mr Bennett", Analysis, 26 (1966), see p. 64 below. 
Smith that Jones' failure to rescue him when he could have done so will fail to be a contributory cause of Smith's aquatic demise. But of course if nothing could save Smith then it is not true that Jones could have saved him and so Jones does not appear in the causal story at all.

Mack partly sees this because his final argument against negative causation makes use of this very point:

There is something very peculiar about including absences of preventing or thwarting events among the necessary causal conditions for outcome $Y$. For any prevention of $Y$ will operate by falsifying part of the citation of jointly sufficient condition for $Y$ - where this citation does not include the absence of preventing events. But that no such falsifying prevention obtains is implied by the satisfaction of the initial statement of jointly sufficient conditions. There is no absence of prevention which stands as a further causal condition. (ibid.)

But of course it doesn't have to stand as a further causal condition. It is a causal condition which as Mack admits is part of the causal landscape and which is brought into prominence when the "sufficiency" of that initial statement of "jointly sufficient conditions" is called into question by our interest in their non-prevention.

Mack of course does not believe that omissions can ever have consequences and his quarrel with those he calls negative-action theorists is not, as sometimes appears, that they have incorrectly characterised the conditions for negative causation; rather he denies that there are ever any such conditions. Mack insists that "the notions of averting and preventing presuppose that sometimes we can enter into causal streams in which we otherwise would have no place" (p. 259), and he insists moreover that this presupposition is illicit.

It comes down to this. Mack's world contains only the setting in motion of trains of events where previously all was at rest. But the real world of action is busy with trains of events, some we have the power to set in motion, others are already in motion (whether caused by other agents or by the brute forces of nature) and we have the power to stop them or, by operating or not operating the points, determine where they will end up and what damage they will do on the way. To deny this is, as I hope I have shown, more embarrassing than to be saddled with "unending liberality in awarding causal status to non-occurrences".

\section{II}

A similar stand against negative actions and against the consequentialist morality in which they figure is taken by Elazar Weinryb, who claims that we are not responsible for the consequences of our omissions or negative actions because these are not genuine actions and therefore cannot have consequences (op. cit., note 1). Thus Weinryb would share Mack's difficulties with the liar example with which we began, but the centre of his argument is his insistence on the physical nexus as the only genuine basis for achieving effects in the world. The potency of the image of the nexus is supplemented by a logical argument and coupled with a rejection of the same point of Professor Anscombe utilised by Mack.

In a famously curt reply to Jonathan Bennett, G. E. M. Anscombe (op. cit., note 6) made the following point: "The nerve of Mr. Bennett's argument is that if A results from you not doing B, then A results from whatever you do instead of $B$. While there may be much to be said for this view it does 
not seem right on the face of it." Weinryb accepts that if Anscombe's Bennett is right, then there is no problem about omissions, they can be treated as the actions that were performed instead, and so "can be evaluated and questions about the responsibility incurred can be raised no less than in the case of actions" (p. 7).

Weinryb accordingly offers a definition of "refraining" which does not refer to bodily movements, believing that he has thereby shown that refrainings or omissions are not actions. First, it is far from clear (unless it is simply a matter of stipulation) that I cannot act without moving my body. It seems perfectly proper to say, in the example with which we started, that I saved your life by keeping silent (and immobile), that both keeping silent and saving your life were things that I did. Moreover, we can respond to the command "Keep still"; keeping still is something that we can do!"

But in any event, cases of complete immobility will be rare. What do we conclude about those cases in which we are doing something with our bodies when our refraining from a life-saving act results in death? Why should we not say that, if you die when I could have saved you, your death was a consequence either of my not saving you or of my drinking coffee instead - my not saving you was my drinking coffee instead? Weinryb's first move is to say that although I was doing something, I was inactive with respect to your death, that is, active only with respect to drinking coffee. He seems to see how unsatisfactory this is and later makes the point turn rather on the visibility of causal connections.

Weinryb concedes that a surgeon might simply be sipping coffee when he could have been performing a life-saving operation and says: "I do not see how the fact that coffee is being sipped by somebody can determine causally someone else's dying"' (p. 13). History and folklore are replete with eloquent refrainings which are immediately intelligible, and their passing into legend testifies to their comprehensibility as well as to their charm. When someone pointedly turns their back on an event, or washes their hands of it, or puts a telescope to their blind eye, it does not require much imagination to see the connection between these actions and what then occurs. What makes the connection is of course that we can immediately see that if people had not behaved in these ways others would not have died. The fact that one needs to know the context in order to make the connection between coffee sippings, hand washings and blind telescope viewings on the one hand, and death by neglect, death by crucifixion and the defeat of a fleet on the other, does not mean that there is no such connection.

All of these events are an essential part of the causal explanation of how it came about that people died or a fleet was defeated. Not only would the deaths and defeats not have occurred without these expressive refrainings, but they would be inadequately explained without reference to them. If the causal connection between negative actions and their consequences is to be severed it needs more in the way of argument than the inability to see connections that have been perspicuous for over two millenia.

We should note that such myopia can break even the sorts of causal chains that Weinryb himself would allow. I signal to the technician not to turn on the respirator, so he goes on sipping his coffee and the patient dies. Since Weinryb cannot see how the fact that coffee is being sipped can determine causally someone else's dying, he also cannot see how my signal can be thus causally connected; since the connection is broken by the coffee

${ }^{7}$ Try it for yourself, it can take some doing! 
sipper, who is active only with respect to drinking coffee. So the argument must turn on Weinryb's championship of the nexus and the logical argument with which he supports it.

"If no bodily movement is necessarily involved in omission", asks Weinryb, "how is it possible for the omission to have effects in the concrete world?" And later it is laid down as a "basic premise of action theory that a bodily movement is necessarily present in every action" (p. 3). Weinryb's point is that it is quite impossible to attribute cracks in the concrete of reality to persons, unless they can be traced to a good hard blow with the sledgehammer of bodily movements. Absence of sufficient water in the mix won't account for it, nor will failure to mix the concrete at all! Weinryb's billiard-ball world of action contains no eloquent silences, no pregnant pauses. I cannot insult someone by ignoring them because my "cutting them dead" might take the form of complete immobility. My decisions, if unaccompanied by movements, have no consequences. In Weinryb's world, droughts do not cause the failure of the harvest, unless perhaps they are acts of God. But of course God's "staying his hand" is not on Weinryb's account something that God does! More prosaically, in elections, abstention is not a course of action available to voters, nor do abstentions have any impact on election results.

There is still, however, Weinryb's "logical argument" and to this we must now turn.

Whenever an agent performs an action, an event occurs such that the truth of the assertion that it occurs is a logically necessary condition for the truth of the given action-description. Thus, 'The window opened at $t$ ' is logically entailed by the action-description ' $I$ opened the window at $t$ '. Had it not ultimately been the case that the window opened at $t$, it could not have been true that I opened it at $t$. (p. 5)

For Weinryb, the beauty of this account is that "refrainings do not have results . . . there is no event in the world, the description of which necessarily becomes true, when it is truly asserted that someone is refraining from performing a certain action" (p. 8). Isn't there though? Whenever an agent performs a negative action, an event occurs such that the truth of the assertion that it occurs is a logically necessary condition for the truth of the given negative action description. Thus 'He died' is logically entailed by the negative action description 'I let him die'. Had it not ultimately been the case that he died it could not have been true that I let him die. This could of course be expressed in Weinryb's preferred language of "refrainings": 'I refrained from preventing his death'.

Now of course Weinryb might say that the important difference is that 'I refrained from operating' does not entail 'He was not operated on'. This is true, though we can say: 'But for my refraining to operate he would have lived' does entail 'He died'. The point is that 'I refrained from operating' is a very squeezed-down negative-action description and we should no more expect it to entail 'He was not operated on' than we should expect 'I moved my finger' to entail 'I shot him'. All that needs to be true for Weinryb's point to be false is that there is some negative action description which entails the relevant consequences, not that any such description does. Weinryb himself admits (p. 9) that there is no simple way of limiting how far action descriptions may be expanded, and he suggests no such way; so 
unless my negative-action descriptions can be shown to be illegitimate, the logical argument cuts both ways.

Weinryb takes it as a basic truth for which he offers no argument that "the agent's performing a primitive action is a necessary condition of attributing agency to him". And again, "a man is responsible for a harm if he has performed some basic action the result of which is causally connected with the given harm" (p. 9), and since he further believes that all basic or primitive actions involve bodily movements he has stipulated himself halfway home and dry. (Halfway because without Weinryb's other arguments it allows coffee sipping to have consequences, but rules out the consequential immobility of our opening example.) But is there any compelling reason why we should accept all this? It doesn't generate a rigorous theory of action nor is it apparently any part of a more useful theory of causation. Action theory has concerned itself almost exclusively with positive actions and so we should not expect "discoveries" made in the light of an investigation of positive actions to be necessarily applicable to negative action.

Apart from stipulation, what is against our saying that negative actions are more simple or more sophisticated than positive actions? 'I let him die' is an adequate negative-action description, and whether on a particular occasion my letting him die was my sophisticatedly playing chess or my simply remaining inert matters not at all.

Weinryb, like Mack, will only allow us to set trains in motion, but he goes further in only permitting us to do so via bodily movements. But we can determine outcomes by not intervening as effectively as we can by bodily movements. We have in short two equally effective ways of determining how things will turn out.

If the causal connexion between negative actions and their consequences cannot be severed and if we are still, in the absence of acceptable excuses, responsible for what we do, then our actions both positive and negative are fully morally assessable and we do not need to resort to Weinryb's positive recommendation that we direct our moral criticism solely towards the thoughts of the Bad Samaritan and not towards his deeds.

We need and may still lack an adequate theory of negative actions, but their causal efficacy no more waits upon this than it was true that agency first appeared in the world with Donald Davidson. ${ }^{8}$

\section{III}

In a gallant attempt to side-step the sort of debate that has just been going on between those who accept that harm may be caused negatively and those that do not, Douglas Husak formulates and then criticises what he calls the "causal argument" (op. cit., note 3). His formulation goes like this:

(1) No one should be held liable for harm he has not caused.

(2) A failure to avert harm is not a cause of harm.

(3) Therefore no one should be held liable for harm he has failed to avert.

Premise (1) of this argument will be called the causal assumption, premise (2) will be called the principle of causal efficacy. (p. 320)

Basically Husak's line is that if we reject the former we don't have to

8I develop a more detailed account of negative actions in my Violence and Responsibility, in which I also try to show why recommendations like those of Weinryb that we morally assess only the thoughts or intentions of Bad Samaritans cannot do the work required of them. See particularly Chs. 3 and 4. 
bother with the latter, and so are free to hold people liable for harm on other grounds. Certainly, so far so good. Although Husak finds at least one, there can be few people who hold the causal assumption. As Husak is aware, there are many other ways in which people can be held liable for harm besides causing it. Those of us who still adhere to negative causation do so because we think it's true and because its truth is very often the reason why we are liable for harm we fail to prevent, not because there is no other way to extend liability and improve the world.

While Husak is rightly critical of the causal assumption he also wishes to reject what he calls "the causal relevance principle", the view that, as Hart and Honoré have said: "statements that a person caused harm" are "one sort of non-tautologous ground or reason for saying that he is responsible".9 This is a principle much more widely held than the causal assumption and Husak wants to dispense with it by suggesting that we are never responsible for harm we have caused simply because we have deliberately and intentionally caused it. Although he sketches a procedure by which this claim might be defended he does not actually defend it that way, both because he is unable to provide appropriate examples and because he has a better criterion of responsibility to offer.

While declaring himself to "be impressed by the strong positive correlation between cases in which the action of $A$ causes harm $x$ and cases in which $A$ is properly held liable for $x$ " (p. 326), Husak believes that this correlation can be absorbed within a larger principle. He suggests that "perhaps the plausibility of the causal relevance principle can be explained by the fortunate fact that we have control over most of the harm we cause and no control over most of the harm we do not cause" (ibid.).

Husak gives no further account of what he understands by "control", so it is difficult to know whether this concept depends in some of its applications on causation or whether it is wholly independent. Indeed, it is unlikely that the idea of control rather than causation will effectively side-step the controversy of which this paper is a part, since both Weinryb and Mack would almost certainly want to know how the agent exercised his control and what its precise mode of operation was. Any defence of a principle like control would begin to look very much like the sorts of defence that are given to the idea of negative causation.

Another difficulty with control as a replacement for causation is that it seems to be a much stronger and so more exclusive notion. One may for example be a contributory cause, but normally one either is in control or one is not. If " $A$ has control over whether or not harm $x$ occurs" (ibid.), then it must be up to $A$ and to no one else, whether or not $x$ occurs. In the only case Husak cites in illustration of his principle, a bystander is liable for the fate of a canoeist who drowns because of the bystander's failure to rescue him. Now it seems natural to think of this as a causal 'because', though not necessarily to think of the bystander as in control, although he does determine the outcome. For one thing he cannot guarantee the demise of the canoeist. What if another equally callous bystander was watching events from the opposite bank? One would not now think of $A$ as being in control of the canoeist's fate because he can still be rescued by $B$. If $A$ and $B$ do not notice one another, both may wrongly believe themselves to control the fate of the canoeist. But if both let the canoeist drown, then though neither was in control, both are responsible.

${ }^{\circ H}$. L. A. Hart and A. M. Honoré, Causation in the Law (Oxford, 1959). 
Husak's use of the term 'control' is ambiguous between control in the sense of determining how things stand in the world, and being fully aware of just what it is we are controlling. This ambiguity comes out in the case where we do have control over whether or not harm occurs but are none the less not liable; where we genuinely and with good reason thought we were allowing a bear to drown whereas in reality it was our grandfather in a fur coat. This ambiguity shows, I think, that Husak's criterion so far from being an improvement on Hart and Honorés causal relevance principle, is precisely that principle. For Hart and Honoré's claim is that being causally responsible for harm in the absence of excusing conditions renders one "liability respon. sible" for harm. The parallel is that Hart and Honoré would call "control over whether or not harm $x$ occurs" "causing harm" and they would call reasonable ignorance of the reality of what was being done an "excusing condition".

But this ambiguity also shows that Husak's criterion cannot play the role he assigns to it, for Husak claims:

the proposition ' $A$ 's action caused harm $x$ ' $(p)$ is not the best reason for believing the proposition ' $A$ is responsible for harm $x$ ' $(q) . p$ fails to be the best reason for believing $q$ when there is some other proposition $r$ that correlates more strongly with $q$ in the sense that (1) $q$ is true when $r$ is true but $p$ is false; and (2) $q$ is false when $r$ is false but $p$ is true. The proposition ' $A$ has control over whether or not harm $x$ occurs' satisfies these conditions when substituted for $r$. (ibid.)

But where we refrain from rescuing our grandfather in a fur coat believing him reasonably and sincerely to be a bear, then $q$ is not true when $r$ is true but $p$ is false. For since Husak uses 'liability' and 'responsibility' interchangeably, we are in this case not liability responsible for grandpa's death but we are in control and we are not (according to Husak) the cause of his death.

Husak is certainly right to think that we do sometimes control the fate of others when we fail to save them from harm, but I would claim that more often we do not. But in all cases where we fail to save those we could save we are causally responsible for their fate; they die because we do not help them. I do not think that any of the arguments so far produced show that this is not a causal 'because'. Negative actions, it is true, may not (always?) be efficient causes. Sometimes they are rather inefficient, but then happily (or sadly) so are positive actions.

\section{University of Manchester}

